\title{
Thymomodulin in association with antifungal drugs in the therapy of cats with disseminated cutaneous sporotrichosis: a prospective study
}

\author{
Gustavo Soares Forlani ${ }^{*}$ (iD) Risciela Salardi Alves de Brito ${ }^{2}$ (D) Jéssica Paola Salame ${ }^{2}$ \\ Angelita Reis Gomes ${ }^{3}$ (D) Fábio Raphael Pascoti Bruhn ${ }^{3}$ (D) \\ Isabel Martins Madrid ${ }^{4}$ (D) Márcia de Oliveira Nobre $^{5}$ (iD)
}

${ }^{1}$ Departamento de Clínicas Veterinárias, Universidade Comunitária do Oeste Catarinense (Unochapecó) 89809-900, Chapecó, SC, Brasil. E-mail: gustavo.forlani@unochapeco.edu.br. "Corresponding author.

${ }^{2}$ Programa de Pós-graduação em Ciências Veterinárias, Universidade Federal de Pelotas (UFPel), Pelotas, RS, Brasil.

${ }^{3}$ Departamento de Veterinária Preventiva, Faculdade de Veterinária, Universidade Federal de Pelotas (UFPel), Pelotas, RS, Brasil.

${ }^{4}$ Prefeitura Municipal de Pelotas, Departamento de Zoonoses, Universidade Federal de Pelotas (UFPel), Pelotas, RS, Brasil.

${ }^{5}$ Departamento de Clínicas Veterinárias, Faculdade de Veterinária, Universidade Federal de Pelotas (UFPel), Pelotas, RS, Brasil.

ABSTRACT: Feline sporotrichosis is a relevant mycose in veterinary medicine due to its severity and zoonotic potential and the fact that it can be difficult to treat. The immune status of the animal exerts influence on the prognosis of the disease and determines its clinical outcome. This study evaluated the efficacy of the immunomodulatory thymomodulin as an adjunct to antifungal therapy in cats with disseminated sporotrichosis; thymomodulin was used in association with itraconazole (ITL) and potassium iodide (KI) to treat this fungal disease in the feline patient. Thirty-one cats $(n=31)$ diagnosed with disseminated cutaneous sporotrichosis were divided into two groups as follows: Group 1 (G1) ( $n=16)$, which included those animals that were treated with thymomodulin in association with ITL and KI, and Group 2 (G2) ( $n=15)$ which had pacientsthat received ITL and KI only. The response to different treatment modalities was assessed, considering the survival rate, time frame for the lesions to respond to therapy, and clinical improvement or deterioration according to a body condition score system. Animals from $G 1$ had a survival rate of nearly 100\% (93.6\%) that was approximately twice higher than the survival rate of those animals from G2 (53\%). Moreover, patients from $G 1$ had a significantly better prognosis, improved body condition, and shorter time for remission of the extra cutaneous clinical signs $(p<0.02)$. Our findings showed that the association of thymomodulin with ITL and KI improves the prognosis of cats with disseminated cutaneous sporotrichosis.

Key words: Sporothrixschenkii complex, clinical study, immunomodulators, antifungal therapy, zoonosis, feline.

Associação de timomodulina na terapia de gatos com esporotricose cutânea disseminada: um estudo prospectivo

RESUMO: A esporotricose é uma das micoses de maior relevância na medicina veterinária, tanto pela sua gravidade, seu potencial zoonótico e seu dificil tratamento. Sabe-se que o aspecto imunológico do gato representa um fator prognóstico determinante. O objetivo desse trabalho foi avaliar a eficácia do imunomodulador timomodulina como adjuvante a terapia antifúngica, itraconazol (ITL) com iodeto de potássio (KI), em gatos com esporotricose disseminada. Trinta e um gatos $(n=31)$ com esporotricose cutânea disseminada foram segregados em dois grupos, o grupo 1 (G1) (n=16) tratado com ITL, KI associada à timomodulina e o grupo 2 (G2) (n=15) apenas ITL e KI. Foi avaliada a resposta clínica aos diferentes tratamentos, levando em consideração a taxa de sobrevivência, tempo de resposta das lesões e progressão do escore de condição corporal. O G1 apresentou taxa de sobrevivência de quase 100\% (93,6\%), aproximadamente o dobro do encontrado no G2 (53\%). Mais que isso, o G1 demonstrou significativamente melhor prognóstico, aprimoramento do escore de condição corporal e menor tempo para remissão dos sinais clínicos extracutâneos (p<0,02). Sendo assim, a associação da timomodulina ao ITL e KI melhora o prognóstico de gatos com esporotricose cutânea disseminada.

Palavra-chave: complexo Sporothrixschenkii, estudo clínico,imunomoduladores, terapia.

\section{INTRODUCTION}

Sporotrichosis is a cosmopolitan disease which is described as an acute or chronic implantation mycosis and is caused by pathogenic clades of Sporothrix spp. (FERREIRA et al., 2019). In Brazil $S$. brasiliensis is the most prevalent species of Sporothrix (NASAKU et al., 2020). It is closely associated with the zoonotic transmission through scratches and bite wounds inflicted by infected cats
(GREMIÃO, 2015). The number of cases of human and animal sporotrichosis in the country has been increasing exponentially recently (PEREIRA et al., 2014). The increase in disease prevalence is due to many factors including the virulence of the pathogen - $S$. brasiliensis is the most virulent species in the $\mathrm{S}$. schenckii complex (ARRILLAGA-MONCRIEFF et al., 2009; FERNANDES et al., 2013; DELLA TORRE et al., 2017) - difficulty for treating this mycotic disease, therapeutic time frame, zoonotic potential, 
and the large numbers of non-domiciled and semidomiciled (stray) cats that are affected by this fungal infection. All these factors make sporothricosis a public health problem in Brazil, which is especially alarming in the States of Rio de Janeiro, Minas Gerais and Rio Grande do Sul (POESTER et al., 2018; GREMIÃO et al., 2020; MACÊDO-SALES et al., 2020; NAKASU et al., 2020; RODRIGUES et al., 2020).

Clinically the disease starts with an ulcerative and/or nodular skin lesion at the inoculation site and may progress to widespread cutaneous lesions evolving over time into a systemic disease with internal organ involvement such as the lungs, liver and bones. In particular, feline patients typically present with high fungal loads in skin lesions with a tendency to form granulomas. These animals are unable to fight off the pathogen and fail to stop its dissemination. In addition, it is known that a decrease in CD8+ cells and a failure of the cellular immune response in feline patients both play a fundamental role in the occurrence and clinical outcome of this disease (MIRANDA et al., 2013; MIRANDA et al., 2016).

Considering the role of cellular immunity and modulation of granulomatous inflammation, drugs that aid the immune system may be particularly beneficial for these patients. Thymomodulin is a thymic extract that promotes the modulation of $\mathrm{T}$ and B lymphocytes and contributes to the action of various defense cell types that are necessary for the control of mycoses e.g. neutrophils, lymphocytes, and macrophages (ANDRADE, et al., 2017; FORLANI, et al., 2018).

Our aim was to conduct a prospective clinical study toin order to assess the efficacy of the association of thymomodulin with the antifungal agentsitraconazole and potassium iodide in the treatment of disseminated cutaneous sporotrichosis in naturally infected cats.

\section{MATERIALS AND METHODS}

Diagnosis; inclusion criteria and exclusion criteria: Study site; diagnosis; inclusion criteria and exclusion criteria:

This study was approved by the Ethics Committee on Animal Experiments (CEEA/UFPel 8442) and was conducted in southern Brazil between 2016 and 2018. Skin samples were collected from cats with cutaneous lesions consistent with sporotrichosis and that were treated at the HCV (veterinary teaching hospital) of the School of Veterinary Medicine from UFPel (Federal University of Pelotas, RS). These samples were submitted for diagnostic workup, which consisted of direct microscopic examination of the specimens and fungal culture at the Center for Diagnosis and Research in Veterinary Mycology of UFPel and at the Mycology Laboratory of FaMed/ FURG (Medical School/Federal University of Rio Grande, RS). After the clinical suspicion of cutaneous sporotrichosis was confirmed by the mycological examination, cats were categorized on the day of the beginning of therapy (M0), based on the distribution of the skin lesions according to the methods published by SCHUBACH et al. (2004) and REIS et al. (2016). The distribution of the skin lesions in these cats was classified as localized (focal) (L1) when there was only one cutaneous lesion in a single site; (L2) when there was a skin lesion in two non-continuous sites (multifocal), and disseminated (widespread) (L3) when there were lesions in three non-continuous sites.

The inclusion criteria of patients in this study were the following: animals at least 1 year of age at the time of the diagnosis of cutaneous sporotrichosis (M0), animals with a clinical presentation of cutaneous sporotrichosis that were classified as L3, and animals that did not have any biochemical changes or clinical signs of other concomitant diseases unrelated to cutaneous sporotrichosis.

Exclusion criteria used in this study were patients under 1 year of age that were classified at the time of the diagnosis of cutaneous sporotrichosis as L1 or L2 and animals presenting biochemical alterations (i.e. changes in alanine aminotransferase, alkaline phosphatase and creatinine levels). Animals that were positive for FIV (Feline Immunodeficiency Virus) and FeLV (Feline Leukemia Virus) were removed from this study only if these animals presented clinical signs either primarily or secondarily linked to the immunosuppression induced by any of these two viruses such as lymphoid neoplasms (lymphoma, lymphosarcoma), chronic gingivostomatitis, bone marrow suppression (anemia, thrombocytopenia, lymphopenia or pancytopenia), and neurological signs (LITTLE et al., 2020).

\section{Experimental groups}

The 31 animals that were selected for this study were randomly selected and distributed into Group 1 (G1) and Group 2 (G2). G1 was composed of 16 cats that received antifungal treatment consisting of itraconazole $100 \mathrm{mg}$ /animal, potassium iodide $5 \mathrm{mg} / \mathrm{kg}$, and thymomodulin $4 \mathrm{mg} / \mathrm{kg}$. G2 was the control group and was formed by 15 cats that received antifungal treatment, which consisted of itraconazole $100 \mathrm{mg} /$ animal and potassium iodide $5 \mathrm{mg} / \mathrm{kg}$. Drugs used in this study included itraconazole (EMS), 
thymomodulin $\left(\right.$ Leucogen $^{\circledR}$ ), and potassium iodide, which were prepared in a compounding pharmacy. All medications in both groups were administered once daily to patients until the end of the treatment (30 days after complete remission of the lesions) or death of the animals. In this study, all animals were fed ad libitum with super premium commercial pet food for adult cats.

During treatment, periodic evaluations were performed according to the following schedule: at the beginning of therapy (M0), 5 to 7 weeks after the beginning of the treatment (M1), and 13 to 15 weeks after starting the therapy (M2). In the animals that presented increased levels of the enzymes alanine aminotransferase (ALT) and/or alkaline phosphatase $(\mathrm{AF})$, hepatoprotective therapy with silymarin from a compounding pharmacy was administered at a dose of $30 \mathrm{mg} / \mathrm{kg}$ once daily until the end of antifungal treatment (REIS et al., 2016). The criterion for clinical cure of cutaneous sporothricosis in our study was based on healing with re-epithelialization of the skin and mucosal lesions, absence of fungal growth in skin lesions submitted for mycological culture, and remission of the clinical signs observed at the time of initial presentation according to the criteria used by REIS et al., (2016).

\section{Clinical evaluation}

Animals were evaluated on the day of initiation of therapy (M0), 5 to 7 weeks after the treatment was initiated (M1), and 13 to 15 weeks after initiation of therapy (M2). The maximum follow-up period was 105 days.

The presence of an extra cutaneous sign suggesting a more severe and systemic disease was considered when one or more of the following signs were present: lymphadenopathy, respiratory signs, and compromised mucous membranes (mucosal involvement) (REIS et al. 2016). The body condition scoring ranged from 1 to 9 (LAFLAMME, 1997). The progression and clinical outcome of the lesions was classified as clinical cure (when there was total regression of the skin lesions), partial improvement (when there was regression in the number or extent of the skin lesions), stability (when there was neither improvement nor worsening of the skin lesions) and worsening when there was an increase in the number or extent/severity of the skin lesions. All patients that died during this study were sent for necropsy. An authorization form (owner consent form for necropsy) was properly completed and signed by the owners in all cases before the submission of these carcasses for postmortem examination. At each stage (M0, M1, and M2), animals were assessed for the presence of extra cutaneous signs, and the progression of the skin lesions and body condition were evaluated according to such schemes.

\section{Zoonotic aspects}

During the first visit to the hospital, owners were informed about the zoonotic potential of the disease and the veterinarian-provided clients with information concerning care and management of infected cats. Recommendations to the client included confinement/isolation of the infected cat from the other animals living in the same household, avoiding handling the sick animal, wearing disposable gloves whenever affected cats were handled, medication administration using veterinary instruments e.g. disposable syringes, and, if necessary, towel restraint during drug administration. At each evaluation stage (M0, M1, and M2), owners were asked whether any other individual (any human being) living in the same household of the infected cat had skin lesions consistent with those of sporotrichosis. In case of an affirmative answer to this question, the owner was instructed to seek medical attention.

\section{Hematological and biochemical evaluation; FIV and FeLV testing}

Blood samples were collected at M0, M1, and M2 for complete blood count and for the analysis of various biochemical constituents including ALT, AF, urea and creatinine.At M0, animals were tested for FIV and FeLV by immunochromatography (ALERE ${ }^{\circledR}$ ).

\section{Statistical analyses}

The number of individuals in each group was calculated using the OpenEpi software considering a confidence level of $95 \%$, power of $80 \%$, and a percentage of those animals treated with thymomodulin of $50 \%$. The Fisher's exact test was used to compare the efficacy of each treatment in G1 and G2 concerning the proportions of qualitative variables, survival or death of the patient, improvement or worsening of body condition, and presence or absence of extracutaneous signs. We used the ANOVA model with repeated measurements for the comparison between laboratory parameters from G1 and G2 which were expressed by quantitative variables between groups and evaluated over time (M0, M1 and M2), The assumptions necessary for the use of these models were considered and evaluated using the Shapiro-Wilk normality test, Levene's homoscedasticity test, and Mauchly's test of sphericity on the endogenous variables included 
in the model in each of the assessments (PESTANA, M.H.; STUTTERER, J.N. 2014). In cases in which no sphericity was observed, corrections of the HuynhFeldt epsilon F test or the Greenhouse-Geisser criterion were used. These tests were applied in the different models present in the study. All statistical analyses were performed using the Statistical Package SPSS $^{\circledR} 20.0$, considering a minimum significance level of $95 \%$.

\section{RESULTS}

This study had 31 cats, 16 of which were included in G1 and 15 in G2. Each group was composed mostly of intact males; G1 was composed of 10 males and 6 females and G2 was composed of 12 males and 3 females. Most cats were young with an average age of 2 years (1-8 years) in G1 and an average age of 3 years in G2 (1-10 years). Complete epidemiological data are presented in table 1.

\section{Clinical evaluation}

All cats included in this study were presented to the clinic with three or more noncontinuous skin lesions and were classified as L3 (disseminated cutaneous sporotrichosis) (SCHUBACH et al., 2004; REIS et al., 2016). In the initial evaluation (M0), 11 cats $(68.7 \%)$ from $\mathrm{G} 1$ and 11 cats $(73.3 \%)$ from G2 presented extracutaneous signs (rhinorrhea, lymphadenitis, compromised mucous membranes and/or lesions in the scrotum or testes).

Clinical follow-up of cats from G1 5 to 7 weeks after the beginning of the treatment (M1)

Table 1 - Characteristics of the 31 cats with sporotrichosis which were established at the beginning (M0) of the treatment of these animals; 16 animals were treated with itraconazole, potassium iodide and thymomodulin (G1) whereas 15 animals were treated with itraconazole and potassium iodide $(\mathrm{G} 2)$.

\begin{tabular}{|c|c|c|c|}
\hline Characteristics of the animals studied & G1 & $\mathrm{G} 2$ & Total \\
\hline Male & $10(62.4 \%)$ & $12(80 \%)$ & 22 \\
\hline Female & $6(37.6 \%)$ & $3(20 \%)$ & 9 \\
\hline \multicolumn{4}{|l|}{ Reproductive status } \\
\hline Neutered & $5(31.3)$ & $8(53 \%)$ & 13 \\
\hline Intact & $11(68.7)$ & $7(47 \%)$ & 18 \\
\hline Age (average in years) & 2,6 & 3 & - \\
\hline \multicolumn{4}{|c|}{ - } \\
\hline FIV-positive & $1(6.2 \%)$ & $1(6.6 \%)$ & 2 \\
\hline FeLV positive & $3(18.7 \%)$ & $4(26.6 \%)$ & 7 \\
\hline FIV/FeLV-positive & $2(12.5 \%)$ & $1(6.6 \%)$ & 3 \\
\hline \multicolumn{4}{|c|}{ 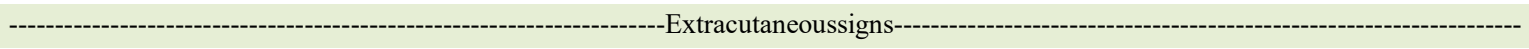 } \\
\hline Present & $11(68.7 \%)$ & $11(73.4 \%)$ & 22 \\
\hline Absent & $5(31.3 \%)$ & $4(26.6 \%)$ & 9 \\
\hline \multicolumn{4}{|c|}{ 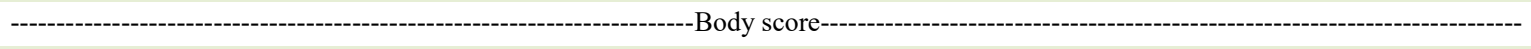 } \\
\hline Score 1 & - & $1(6.2 \%)$ & 1 \\
\hline Score 3 & $9(56.3 \%)$ & $8(53 \%)$ & 17 \\
\hline Score 5 & $7(43.7 \%)$ & $6(40 \%)$ & 13 \\
\hline Scores 7-9 & - & - & - \\
\hline
\end{tabular}

Treatment:

G1 - Potassiumiodide $5 \mathrm{mg} / \mathrm{kg}$, Itraconazole $100 \mathrm{mg} / \mathrm{cat}$, thymomodulin $4 \mathrm{mg} / \mathrm{kg}$;

G2 - Potassiumiodide $5 \mathrm{mg} / \mathrm{kg}$, Itraconazole $100 \mathrm{mg} /$ cat.

FIV Feline Immunodeficiency Virus;

FeLV Feline Leukemia Virus. 
showed that in 1 patient $(6.2 \%)$ the clinical picture worsened and the animal ultimately died, 6 patients $(37.5 \%)$ presented clinical cure, 1 patient $(6.2 \%)$ had no significant improvement or worsening of the medical condition, and in 8 patients $(50 \%)$ there was a decrease in the number or extent of the skin lesions, which characterized clinical improvement.

In the third evaluation that was performed 13-15 weeks (M2) after the beginning of therapy, the condition of 2 patients $(12.5 \%)$ was stable, and there was a complete remission of the cutaneous lesions in 7 patients $(43.7 \%)$ (Figure 1). Thus, at the end of 15 weeks of treatment, 13 patients from G1 attained a clinical cure, the clinical picture improved in 2 patients but clinical cure was not achieved in these patients, and 1 patient died.

The follow-up of animals from G2 at M1 showed that in 7 patients $(43.7 \%)$, the skin lesions worsened and that these animals died, 2 patients $(13.3 \%)$ achieved a clinical cure, and 6 patients (40\%) showed clinical improvement. In the third evaluation (M2), 4 of the 6 cats (26.6\%) that still had clinical signs of the fungal disease achieved clinical cure (Figure 2) whereas 2 cats $(13.3 \%)$ with skin lesions and no significant clinical improvement were considered as being in a stable condition. At the end of 15 weeks of therapy, 6 animals attained a clinical cure, 2 animals showed clinical improvement, and
7 animals died. Analysis of the body condition of patients at M0 showed that in G1 9 animals (56.3\%) were thin (BCS3) and 7 animals (43.7\%) had an appropriate body condition (BCS5). In G2, 1 animal $(6.6 \%)$ was classified as BCS 1,8 animals $(53 \%)$ as BCS 3 , and 6 animals $(40 \%)$ as BCS 5 .

When comparing the progression of BCS between cats from G1 and cats from G2, no difference was reported at M1 ( $>00.05)$. However, at M2 a significant number of cats from G1 improved their BCS $(p<0.02)$. In animals from G1, 7 cats (46.6\%) presented progression from BCS 3 to 5,1 cat $(6.6 \%)$ progressed from BCS 5 to 7 , and the other animals remained within the initial BCS. In G2, 2 cats (13.3\%) presented progression of BCS from 3 to 5,1 animal $(6.6 \%)$ presented regression of BCS from 3 to 1 , and the rest of the animals remained within the initial BCS. Other data and their respective stratified analyses are presented in table 2 .

During this study, 1 cat (6.2\%) from G1 and 7 cats $(46.6 \%)$ from G2 died. The death of these patients occurred in the first 30 days of treatment; 3 animals died during the first week of therapy, 3 animals died during the second week of therapy, and 2 animals died in the fourth week of therapy. In 6 cases, all animals from G2 that died, an authorization for the animal's necropsy was obtained from owners. At postmortem examination, systemic fungal infection

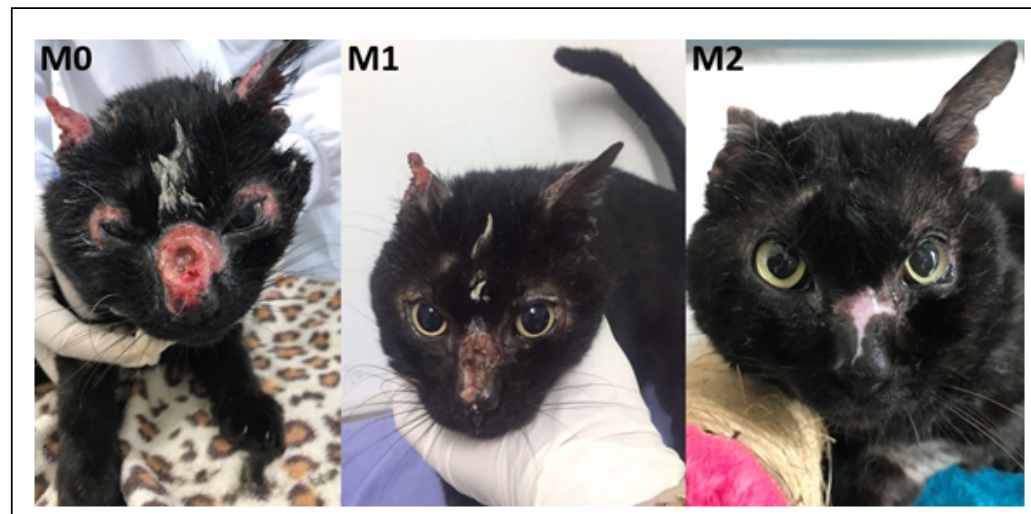

Figure 1 - FeLV/FIV-negative male cat with disseminated cutaneous sporotrichosis. This animal was treated with thymomodulin, itraconazole, and potassium iodide (G1).

Day 0 (M0) Lesions on both pinnae, periocular region, and nasal planum.

Day 40 (M1): All skin lesions significantly decreased in size which indicates meaningful clinical improvement.

Day 92 (M2): Remission of the cutaneous lesions with scarring of the skin as the only sequel of fungal infection (M2). 


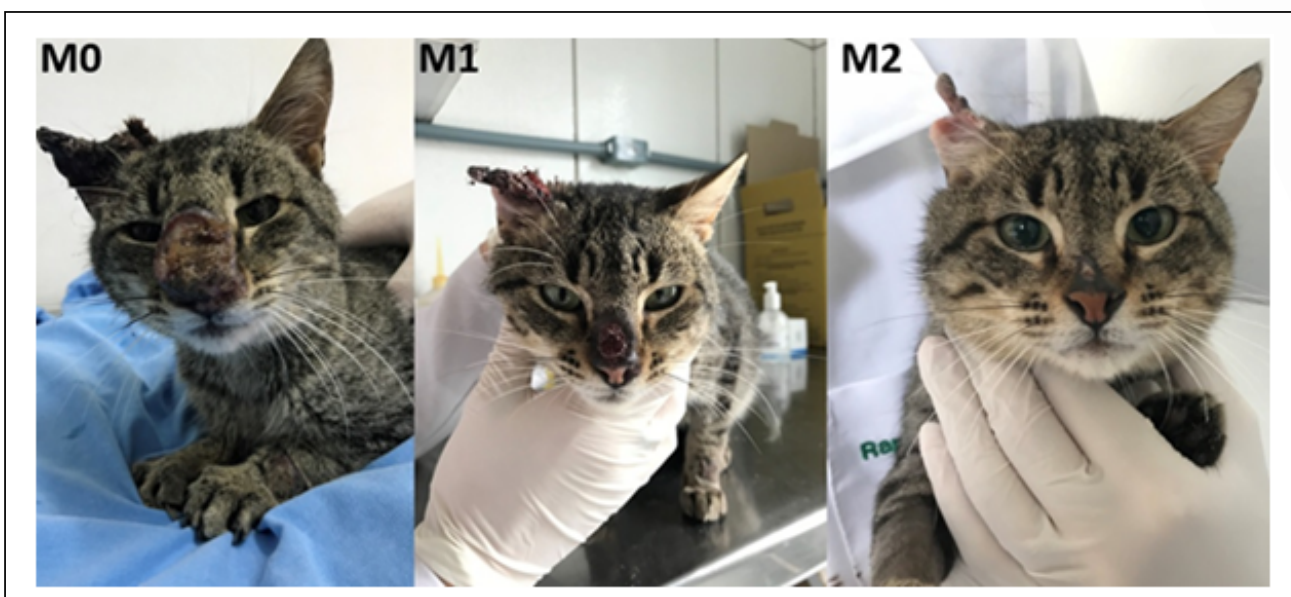

Figure 2 - FIV/FeLV-positive male cat with disseminated cutaneous sporotrichosis, This patient was treated with itraconazole and potassium iodide $(\mathrm{G} 2)$.

Day 0 (M0): ulcerative lesions on the right pinna, nasal planum, and left thoracic limb.

Day 42 (M1): All skin lesions significantly decreased in size which indicates meaningful clinical improvement. Day 96 (M2): Remission of the cutaneous lesions; scarring of the skin was the only sequel of the mycosis (M2).

was observed in 5 animals $(83.3 \%)$. The internal sites affected in those cases of widespread involvement were lung $(\mathrm{n}=5)$, liver $(\mathrm{n}=3)$, bone $(\mathrm{n}=3)$, testis $(\mathrm{n}$ $=3)$, and spinal cord $(\mathrm{n}=1)$.

\section{Zoonotic aspects}

In this study, 6 owners contracted sporotrichosis; 5 of these individuals contracted the disease before a definite diagnosis of cutaneous sporotrichosis in the cat was made by laboratory testing and 1 individual contracted the disease after the mycosis was diagnosed by mycology in the cat. All infected owners reported that they were scratched by their pets and two of these individuals were scratched and bitten as well.

\section{Blood count and biochemical analyses.}

Blood count performed before the beginning of the therapy (M0) showed that mostthe majority of the patients $(87 \%)$ had normal hemocytometer cell counts: animals from G1 had a hematocrit (Ht) [packed cell volume] of $31.2 \%$ and animals from $\mathrm{G} 2$ had aHt (PCV) of $28.9 \%$.

Leukometry results included leukocytosis in $48 \%$ of the animals, and a total leukocyte count (TLC) of $19.3 \mathrm{mil} / \mu \mathrm{L}$ in cats from G1, whereas in cats from $\mathrm{G} 2$ the TLC was $24.4 \mathrm{mil} / \mu \mathrm{L}$.

There was no difference in the TLC or the $\mathrm{Ht}$ between groups before the beginning of the treatment $(\mathrm{p}>0.05)$.
Evaluation of animals 5 to 7 weeks after the beginning of the treatment (M1) showed aHt of $35.1 \%$ in $\mathrm{G} 1$ and aHt of $33.4 \%$ in G2; 1 animal from $\mathrm{G} 2 \mathrm{had}$ anemia. TLC was $18.2 \mathrm{mil} / \mu \mathrm{L}$ in animals from G1 and $19.1 \mathrm{mil} / \mu \mathrm{L}$ in animals from $\mathrm{G} 2$; leukocytosis was observed in 5 animals from G1 and in 4 animals from $\mathrm{G} 2 ; 13$ to 15 weeks after the beginning of therapy (M2), animals from G1 had a $\mathrm{Ht}$ of $34.8 \%$ whereas animals from $\mathrm{G} 2$ had a Ht of $33.6 \%$; anemia was not seen in any of these animals. TLC was 18.5 $\mathrm{mil} / \mu \mathrm{L}$ in cats from $\mathrm{G} 1$ whereas TLC was $17.8 \mathrm{mil} / \mu \mathrm{L}$ in cats from G2; leukocytosis was noted in 3 animals from group $\mathrm{G} 1$ and in 2 animals from G2. There was no significant difference between TLC, lymphocyte count, lymphocyte morphology or Ht from G1 and G2 during treatment $(\mathrm{p}>0.05)$.

At the first evaluation (M0), the biochemical parameters of the patients were within normal ranges. However, at the second evaluation (M1), 8 patients from G1 had high ALT levels ( $\overline{\mathrm{x}}=$ 121.9 IU/L), 9 patients had increased AF levels ( $\overline{\mathrm{x}}$ $=136.4 \mathrm{IU} / \mathrm{L}$ ), and 5 patients from G2 had elevation in both $\operatorname{ALT}(\overline{\mathrm{x}}=166.9 \mathrm{IU} / \mathrm{L})$ and $\operatorname{AF}(\overline{\mathrm{x}}=155.4 \mathrm{IU} / \mathrm{L})$ levels. At assessment M2, 6 animals from G1 had an increase in both ALT ( $\overline{\mathrm{x}}=140.8 \mathrm{IU} / \mathrm{L})$ and AF ( $\overline{\mathrm{x}}$ $=177.3 \mathrm{IU} / \mathrm{L})$ whereas animals from animals from $\mathrm{G} 2$ had ALT $(\overline{\mathrm{x}}=149.4 \mathrm{IU} / \mathrm{L})$ and $\operatorname{AF}(\overline{\mathrm{x}}=219.1 \mathrm{IU} / \mathrm{L})$. There was a significant increase in ALT and AF levels in both groups when M0 was compared with M1 and M2 $(p<0.04)$. There was no difference between the groups though. 
Table 2 - Stratified analysis of the clinical features presence or absence of extracutaneous signs, positive or negative for retroviruses (FelV/FIV), and body condition score] of 31 cats with sporotrichosis - 16 cats from G1 and 15 cats from G2 - and influence of each clinical feature on the clinical outcome (death) in these patients.

\begin{tabular}{|c|c|c|c|c|}
\hline Clinical Features (CF) & Group & Number of cats with a given $\mathrm{CF}$ that died & Total cats with a given $\mathrm{CF}$ & $P$ value \\
\hline \multirow{2}{*}{ Presence of E.C.S. } & G1 & $1 \mathrm{a}$ & $11 \mathrm{a}$ & \multirow{2}{*}{0.02} \\
\hline & $\mathrm{G} 2$ & $7 b$ & $11 \mathrm{a}$ & \\
\hline \multirow{2}{*}{ No E.C.S. } & G1 & - & $5 \mathrm{a}$ & \multirow{2}{*}{1.00} \\
\hline & G2 & - & $4 a$ & \\
\hline \multirow{2}{*}{ FIV } & G1 & - & $3 \mathrm{a}$ & \multirow{2}{*}{1.00} \\
\hline & G2 & - & $2 \mathrm{a}$ & \\
\hline \multirow{2}{*}{ FeLV } & G1 & $-\mathrm{a}$ & $3 a$ & \multirow{2}{*}{0.4} \\
\hline & $\mathrm{G} 2$ & $2 \mathrm{a}$ & $3 a$ & \\
\hline \multirow{2}{*}{ FIV/FeLV } & G1 & $-\mathrm{a}$ & $1 \mathrm{a}$ & \multirow{2}{*}{1.00} \\
\hline & $\mathrm{G} 2$ & $1 \mathrm{a}$ & $2 \mathrm{a}$ & \\
\hline \multirow{2}{*}{ Retrovirusfree } & G1 & $1 \mathrm{a}$ & $9 a$ & \multirow{2}{*}{0.2} \\
\hline & G2 & $3 a$ & $8 \mathrm{a}$ & \\
\hline \multirow{2}{*}{ B.C.S. 1-3 } & G1 & $1 \mathrm{a}$ & $8 \mathrm{a}$ & \multirow{2}{*}{0.01} \\
\hline & G2 & $7 b$ & $9 a$ & \\
\hline \multirow{2}{*}{ B.C.S. 5} & G1 & - & $7 \mathrm{a}$ & \multirow{2}{*}{1.00} \\
\hline & G2 & - & $6 a$ & \\
\hline
\end{tabular}

Treatment:

G1 - Potassiumiodide $5 \mathrm{mg} / \mathrm{kg}$, Itraconazole $100 \mathrm{mg} / \mathrm{cat}$, thymomodulin $4 \mathrm{mg} / \mathrm{kg}$;

$\mathrm{G} 2$ - Potassiumiodide $5 \mathrm{mg} / \mathrm{kg}$, Itraconazole $100 \mathrm{mg} / \mathrm{cat}$.

CF Clinical Feature.

B.C.S. Body condition score.

E.C.S. Extracutaneous signs;

FIV Feline Immunodeficiency Virus;

FeLV Feline Leukemia Virus.

- no animals with a certain feature died;

a, b Different letters mean statistical difference between groups in a given characteristic (with a $95 \%$ confidence interval).

There wereno changes in serum creatinine levels during this study; 2 patients from G1 and 1 patient from G2 had slightly increased urea levels at M2. There was no statistical correlation between hematological and biochemical alterations and death of the animals $(\mathrm{p}>0.05)$.

\section{Immunochromatography for FIV and FeLV.}

Immunochromatographic evaluation for FIV and FeLV was performed in all animals from this study at M0. In G1, 3 patients were positive for FeLV, 3 patients were positive for FIV, and 1 patient was positive for both rules. In G2, 3 patients tested positive for FeLV, 2 patients tested positive for FIV, and 2 patients tested positively for both viruses.

\section{DISCUSSION}

This is the first prospective controlled clinical study that evaluated the therapeutic potential of thymomodulin for treating feline diseases. Animals from $\mathrm{G} 1$ that received thymomodulin associated with antifungal therapy presented a statistically higher survival rate than animals from $\mathrm{G} 2(\mathrm{p}<0.02)$. This finding unprecedentedly demonstrates that the use of thymomodulin improves the prognosis of cats with disseminated cutaneous sporotrichosis. In a case report previously published elsewhere, the use of thymomodulin was shown to be useful for treating a FeLV-positive cat with sporotrichosis (FORLANI et al., 2018). Our results encourage the use of 
thymomodulin for treating feline diseases. We are not aware of any manuscript published in the veterinary literature to date about a similar controlled study in which the therapeutic potential of this compound in cats was evaluated.

In this study, the highest rate of therapeutic success of cats with sporothricosis from G1 was credited to the modulation of $\mathrm{T}$ and $\mathrm{B}$ lymphocytes and the appropriate functioning of defense cells against fungal infections including neutrophils and macrophages converging with the immunomodulatory mechanism employed by thymomodulin (ANDRADE, S. 2017). This compound has been used for treating a range of infectious diseases in humans, including Acquired Immune Deficiency Syndrome (AIDS), cancer and bronchopneumopathy; its use in the therapy of these illnesses positively modulates the proportion of $\mathrm{CD} 3+, \mathrm{CD} 4+$ and $\mathrm{CD} 8+$ cells improving the prognosis of these patients (ROUX et al., 2003; GARRITANO, 2007).

The body condition score the improvement of such score proved to be an important prognostic factor. In M0, when animals with BCS lower than 5 $(\mathrm{n}=18)$ - 9 animals from each experimental group had such scores - with animals with an appropriate BCS $(n=13)-7$ from G1 and 6 animals from G2 had such score - we noted that those animals with a lower BCS had a higher death rate $(n=8)$, i.e. 7 animals from G2 and 1 animal from G1 with a lower BCS died.

It was reported that a greater number of animals from G1 $(\mathrm{p}<0.02)$ could restore adequate $\mathrm{BCS}$ during treatment. Based on these findings, we may infer that, by contributing to the immunological homeostasis of cats, these animals become less vulnerable to the inherent catabolism of mycoses with the formation of exuberant pyogranulomatous lesions. There is evidence that patients who receive a high nutritional diet have a better prognosis (BOBECK, 2020).

Another prognostic factor in our study was that the presence of extra cutaneous signs was significantly associated with the death of patients as it was observed in $100 \%$ of the animals that died. Stratification only of cats with extra cutaneous signs showed a significant difference in the recovery of cats from G1 compared with cats from G2. The best therapeutic response of these patients is probably associated with thymic extract derivatives which enhance and boost acquired immunity, especially due to their ability to increase lymphocyte count and functionality (NK and CD4+/CD8+ cell ratio) (IOANNOU et al., 2012). In cats with sporotrichosis, the number and functionality of CD8+ cells are particularly important especially due to a decrease in CD8+ cells which is significantly associated with the most severe clinical manifestation of the disease (MIRANDA, et al., 2016). It represents a determining factor for the hematogenous dissemination of this fungal pathogen resulting in poor prognosis of the patient.

As anticipated, in the present study groups were composed mostly of young intact males. Sporotrichosis is transmitted between cats mainly during fights. Such behavior is extremely common in intact tomcats with free access to streets. Bite and scratch wounds inflicted on each other during these fights create a portal of entry for this pathogen in the skin damaged by trauma. The sharp and pointed teeth and nails inoculate the fungus deep into the skin of injured animals. The profile of these cats also predisposes them to retrovirus infections such as FIV and FeLV. In this study, retroviruses did not influence the prognosis of patients. Our findings corroborate with those of studies previously published by other researchers that similarly did not find any interference of retroviruses on the prognosis of feline cutaneous sporotrichosis (REIS et al., 2012; REIS et al., 2016). However, it is worth mentioning that those FelV-positive and/or FIV-positive patients did not present any clinical signs consistent with FIV and/or FeLV infection or overt disease associated with such viral infections whenever these cats were clinically evaluated during the study. Therefore, it is suggested that although these cats were positive for one or both of these retroviruses, these animals were still in the asymptomatic (subclinical) stage of viral infection. Thus, it is unsafe to infer that symptomatic patients with immunosuppression, severe anemia or neoplasms will not have a worse prognosis.

In this study, 6 owners contracted sporotrichosis from their cats; 5 of these owners contracted this fungal infection from their animals before the diagnosis of this mycosis in the affected cats was confirmed by laboratory testing, and 1 of these owners acquired this fungal infection after a final diagnosis was made by mycology in a cat. These findings show that even with appropriate management guidelines for drug administration to pets, treatment may still pose a risk to the owner since medication is administered to cats orally and such procedure involves handling of the sick cat daily during the entire course of therapy. Other forms of drug administration, such as the application of intralesional amphotericin B (GREMIÃO et al., 2009) and cryotherapy (SOUZA et al., 2016) are useful in some cases of feline 
sporotrichosis. However, these alternatives do not apply to L3 patients given the fact that the number and extent of the skin lesions in these patients require the administration of systemic antifungals for prolonged periods of time, which may result in unwanted side effects, especially hepatotoxicity (REIS et al., 2016).

There was a significant increase in the mean measurements of the liver enzymes ALT and $\mathrm{AF}$ in animals from both groups as expected due to the hepatotoxic effects of prolonged use of ITL. Many animals from G1 showed an elevation in liver enzymes However, a greater number of animals from G2 died at the beginning of therapy. Therefore, fewer cats from this group received antifungal treatment for a prolonged period, thus lowering the risks of these patients to develop drug-induced liver injury (REIS et al., 2016). Cats from both groups presented episodic vomiting and hyporexia during treatment. The symptomatic management of these patients, associated with the implementation of silymarin, allowed antifungal treatment to be continued, which was fundamental for the patients' clinical progress. The use of silymarin as a hepatoprotective agent was performed in a similar and successful manner in cats with sporotrichosis that received silymarin associated with ITL and KI as reported by other authors (REIS et al., 2012; REIS et al., 2016).

In this study, 8 animals died; permission for a full necropsy was obtained from the owners in 6 out 8 animals; 5 animals develop the disseminated form of this mycosis. The lung was the most frequently affected organ in those cases. In this study, pulmonary sporotrichosis secondary to cutaneous sporotrichosis was observed in all animals that presented the disseminated form of the fungal infection. These findings corroborated those of other researchers that report in previous studies that the respiratory system is the most affected body system in this mycosis and that the systemic spread of the fungal infection is the principal cause of Sporothrix-related deaths in severely affected cats (REIS et al., 2016).

One main limitation of this study is the fact that quantification and follow-up of CD4+ and CD8+ $\mathrm{T}$ cell counts during the serial clinical evaluation of the patients were not performed. In addition to this analysis, the authors suggested that a study assessing the possible effects of thymomodulin on interleukin 10 should be conducted in the near future order on further our knowledge on the treatment of feline sporotrichosis. One previous study demonstrated that cats infected with both retroviruses (FelV/FIV) and that also had sporotrichosis infection had high levels of this particular immunosuppressive interleukin in the blood (MIRANDA, et al. 2018). This could hinder the activation of Th1 lymphocytes favoring the spread of the fungus throughout the body. Thus, modulation of interleukin 10 or CD4+ and CD8+ cells by thymomodulin may establish the beneficial effects of this compound to these patients.

\section{CONCLUSION}

The association of thymomodulin at a dose of $4 \mathrm{mg} / \mathrm{kg}$ with itraconazole $100 \mathrm{mg} / \mathrm{cat}$ and potassium iodide $5 \mathrm{mg} / \mathrm{kg}$ improves the prognosis of cats with disseminated cutaneous sporotrichosis and is particularly useful in those cases in which extracutaneous signs are observed. Disseminated cutaneous sporotrichosis requires long-term treatment and is successful in many cases. However, the disease still has a high mortality rate.

\section{ACKNOWLEDGMENTS}

The authors gratefully acknowledge the Hospital Veterinário of the Universidade Federal de Pelotas (UFPel) and the Laboratório de Microbiologia of UFPel and the Universidade Federal do Rio Grande (FURG) for their support and the Brazilian funding agency Conselho Nacional de Desenvolvimento Científico e Tecnológico $(\mathrm{CNPq})$ for the granting of the Productivity Scholarship 308152/2019-0. And was financed in part by the Coordenação de Aperfeiçoamento de Pessoal de Nível Superior (CAPES), Brasil - Finance code 001.

\section{DECLARATION OF CONFLICTS OF INTERESTS}

The authors of this manuscript state that this study does not present any conflict of interest.

\section{AUTHORS' CONTRIBUTIONS}

All authors contributed equally and substantially to the conception, writing, editing and approval of the final version of this manuscript.

\section{REFERENCES}

ANDRADE, S. F. Quick Consult Manual of Veterinary Therapy. 1st ed. Rio de Janeiro: Roca, 2017. p.240 and p. 317.

BOBECK, E. A. Nutrition and health: Companion animal applications: Functional nutrition in Livestock and Companion Animals to Modulate the Immune Response. Journal of Animal Science, v.98, i3, Mar 2020. Available from: <https://academic. oup.com/jas/article/98/3/skaa035/5728573>. Accessed: Jan. 05, 2020. doi: 10.1093/jas/skaa035.

FERREIRA, B. et al. Determination in the pathogenic fungus Sporothrix spp. Front Microbiol, v.10, p.284-86, fev 2019. Available from: <https://www.frontiersin.org/articles/10.3389/fmicb.2019.00284/ full>. Accessed: Jan. 05, 2020. doi: 10.3389/fmicb.2019.00284.

Ciência Rural, v.51, n.6, 2021. 
FORLANI, G. S. et al. Sporotrichosis in a FeLV-positive cat - case report. ClínicaVeterinária. n.137, p.58-64. Nov-Dec 2018. ISNN: 1413-571X.

GARRITANO, C. R. O. Evaluation of the use of thymic extract (thymomodulin) in patients with malignant neoplasm undergoing surgical treatment. Revista do Colégio Brasileiro de Cirurgia, v.34, n.4, p.225-231, Aug 2007. Available from: <http://www.scielo.br/ scielo.php?script $=$ sci_arttext\&pid $=$ S010069912007000400006\&1ng $=$ pt\&tlng $=$ pt $>$. Accessed: Jan, 05, 2018. doi: 10.1590/S010069912007000400006.

GREMIÃO, I. D., et al. Geographic expansion of Sporotrichosis, Brazil. Emerging Infectious Diseases. Available from: $<\mathrm{https} / /$ wwwnc.cdc.gov/eid/article/26/3/19-0803_article>. v.26 i.3 p621624. 2020. Accessed: Jul, 2020. doi: 10.3201/eid2603.190803.

GREMIÃO, I. D. et al. Case report: intralesional amphotericin $B$ in a cat with refractory localized sporotrichosis. Journal of Feline Medicine and Surgery. v.11, p.720-723. Jan. 2009. Available from: $<$ https://journals.sagepub.com/doi/pdf/10.1016/j. jfms.2009.01.012>. Accessed: Dec. 05, 2017. doi: 10.1016/j. jfms.2009.01.012.

GREMIÃO, I.D. et al. Feline sporotrichosis: epidemiological and clinical aspects. Medical Mycology, v.53, n.1, p.15-21, Dec 2015. Available from: <https://academic.oup.com/mmy/ article/53/1/15/992792>. Accessed: Jun. 05, 2018. doi: 10.1093/ $\mathrm{mmy} / \mathrm{myu} 061$.

HANNAPPEL, E; HUFF, T. The thymosinsprothymosin alpha prathymosin, and beta-thymosins: structure and function. Vitam Horm, v.66, p.257-296, 2003. Available from: <https://www. sciencedirect.com/science/article/pii/S0083672903010070>. Accessed: Jan. 05, 2018. doi: 10.1016/S0083-6729(03)01007-0.

HOSIE, M. J. et al. Feline immunodeficiency. ABCD guidelines on prevention and management. Journal of Feline Medicine and Surgery. v.11, p.575-584, Jul 2009. Available from: $<$ https://www. sciencedirect.com/science/article/pii/S1098612X09001181>. Accessed: Feb. 05, 2018. doi: 10.1016/j.jfms.2009.05.006.

IOANNOU, K. et al. Prothymosin alpha: a ubiquitous polypeptide with potential use in cancer diagnosis and therapy. v.61, p.599-614, May 2012. Available from: <https://link.springer. com/article/10.1007/s00262-012-1222-8>. Accessed: Dec. 05, 2017. doi: $10.1007 / \mathrm{s} 00262-012-1222-8$.

LAFLAMME, D. Development and validation of a body condition score system for cats: a clinical tool. Feline Practice, v.25, p.1317, 1997. Available from: <http://agris.fao.org/agris-search/search. do?recordID=US1997053264>. Accessed: Dec. 05, 2017. ISSN 1057-6614.

LITTLE et al. 2020 AAFP Feline Retrovirus Testing and Management Guidelines. J Feline Med Surg. v.22, n.1, p.530, 2020. Available from: <https://journals.sagepub.com/doi/ pdf/10.1177/1098612X19895940>. Accessed: Jan. 05, 2020. doi: $10.1177 / 1098612 \times 19895940$

LOPEZ-ROMERO, E. et al. Sporothrixschenckii complex and sporotrichosis, an emerging health problem.Future Microbiol.v.6, p.85-102. Available from: $<$ https://www.futuremedicine.com/doi/ pdf/10.2217/fmb.10.157>. Accessed: Jun. 05, 2018. doi: 10.2217 fmb.10.157.
MACÊDO-SALES, P. de, et al. Coinfection of domestic felines by distinct Sporothrixbrasiliensis in the Brazilian sporotrichosis hyperendemic area. Fungal Genetics and Biology, v.140 p.103397, Jul 2020. Available from: <https://www.sciencedirect. com/science/article/abs/pii/S1087184520300888?via\%3Dihub>. Accessed: Jan. 05, 2020. doi: 10.1016/j.fgb.2020.103397.

MIRANDA, L et al. Severe feline sporotrichosis associated with an increased population of $\mathrm{CD} 8^{\text {low }}$ cells and a decrease in $\mathrm{CD} 4+$ cells. Medical Mycology. v.54, p.29-39. Jan 2016. Available from: <https://academic.oup.com/mmy/article/54/1/29/2579514>. Accessed: May, 05, 2018. doi: 10.1093/mmy/myv079.

MIRANDA, L. et al. Co-infection with feline retrovirus is related to changes in immunological parameters of cats with sporotrichosis. PLOS ONE, 13(11). Available from: <https://journals.plos.org/ plosone/article?id=10.1371/journal.pone. $0207644>$. Accessed: Jan. 05, 2020. doi: 10.1371/journal.pone.0207644.

MIRANDA, L. H. M., et al. Feline sporotrichosis: Histopathological profile of cutaneous lesions and their correlation with clinical presentation. Comp Immunol Microbiol Infect Dis. v.36, p.425432. Jul. 2013. Available from: <https://www.sciencedirect.com/ science/article/pii/S0147957113000210>. Acessed: Mar. 05, 2018. doi: 10.1016/j.cimid.2013.03.005.

NAKASU, C. et al., Feline sporotrichosis: a case series of itraconazole-resistant Sporothrixbrasiliensis infection. Braz J Microbiol. 2020. Available from: <https://link.springer.com/ article/10.1007/s42770-020-00290-5>. Accessed: Jan. 05, 2020. doi: 10.1007/s42770-020-00290-5.

PEREIRA, S. A, et al. Response to azolic antifungal agents for treating feline sporotrichosis. Vet Rec., v.166, p.290-294. Mar. 2010. Available from: <https://www.researchgate.net/ profile/Sandro_Pereira/publication/41808690_Response_to azolic_antifungal_agents_for treating feline_sporotrichosis/ links/55df64ae08aecb1a7cc1a135.pdf $>$. Accessed: Oct. 05, 2017. doi: $10.1136 /$ vr.b4752.

PEREIRA, S.A. The epidemiologicalscenariooffelinesporotrichosis in Rio de Janeiro, Stateof Rio de Janeiro, Brazil. Rev Soc Bras Med Trop., v.47, n.3, p.392-393. Jun. 2013. Available from: $<$ http://www.scielo.br/scielo.php?pid=S003786822014005000002 \&script $=$ sci arttext $>$. Accessed: Jan. 05, 2018. doi: 10.1590/00378682-0092-2013.

PESTANA, M. H.; GAGEIRO, J. N. A complementary study programme in data analysis for social sciences using the SPSS (6 $6^{\text {thed}}$. Lisboa 2014.

POESTER, V. et al. Sporothrix spp. evaluation of a hyperendemic area for sporotrichosisinf Southern Brazil. Cienc.Anim.Bras. 2018, v.19: p1-8. Available from: <https://www.scielo.br/pdf/cab/ v19/1809-6891-cab-19-e52571.pdf $>$. Accessed: Jan. 05, 2020. doi: 10.1590/1809-6891v19e-52571.

REIS, E. G et al. Potassium iodide capsule in the treatment of feline sporotrichosis. J Fel Med Surg. v.14, p.399-404, Mar. 2012. Available from: $<$ https://journals.sagepub.com/doi/abs/10.1177/10 98612X12441317? casa token=4BOXIbLwY4sAAAAA\%3AsxO mR9JHEclO8j4VyXKnhHVDTlxBxD9v0eRvgFGblEn8HjhldpV xk7nKKr9rPI76-I-Uv uQ06i2q4Q>. Accessed: Jan. 05, 2018. doi: $10.1177 / 1098612 \times 12441317$. 
REIS, E. G. et al., Association of itraconazole and potassium iodide in the treatment of feline sporotrichosis: a prospective study. Med Mycol, v.54, p.684-90. Available from: <https://academic.oup. com/mmy/article/54/7/684/2222582>. Accessed: Jan. 05, 2020. doi: $10.1093 / \mathrm{mmy} / \mathrm{myw} 027$.

ROUX, M. E., et al. Compartmentalisation between gut and lung mucosae in a model of secondary immunodeficiency: effect of thymomodulin. Int $\mathbf{J}$ ImmunopatholPharmacol., v.16, n.2, p.151-156. May. 2003. Available from: $<$ https://journals.sagepub. com/doi/abs/10.1177/039463200301600209>. Accessed: Dec. 05, 2017. doi: 10.1177/039463200301600209.
SCHUBACH, T.M.P. et al. Evaluation of an epidemic of sporotrichosis in cats: 347 cases (1998-2001). J Am Vet Med Assoc, v.224, p.1623-1629, May. 2004. Available from: $\quad<$ https://avmajournals.avma.org/doi/abs/10.2460/ javma.2004.224.1623>. Accessed: Feb. 05, 2018. doi: 10.2460/ javma.2004.224.1623.

SOUZA, C. P. et al. Cryosurgery in association with itraconazole for the treatment of feline sporotrichosis. Journal of Feline Medicine \& Surgery. v.18, p.137-143, 2016. Available from: <https:// journals.sagepub.com/doi/pdf/10.1177/1098612X15575777>. Accessed: Sep. 05 2017. doi: 10.1177/1098612X15575777. 